\title{
Oil generation from the immature organic matter after artificial neutron irradiation
}

\author{
HuAJIAN WANG, WenZhi ZhaO, ShUichang Zhang
}

Research Institute of Petroleum Exploration and

Development, Beijing, 100083, China

Correspounding author: wanghuajian@petrochina.com.cn

Organic-rich shale often receives high doses of radiation from radionuclides, mostly uranium (U). Natural decay of $U$ releases particles and energy simultaneously. Thermal stress is considered to be conducive to organic matter (OM) maturation and petroleum generation and always taken into account in the simulation of basin thermal evolution. However, for the particles and their bombardment, the effect is still unclear. The main reason is that the half-life of ${ }^{238} \mathrm{U}$ is up to 4.6 billion years, it is impossible to monitor the effect of $\mathrm{U}$ natural decay in laboratory.

Here, we implemented an thermal neutron irradiation experiment in a nuclear reactor using immature Type-II organic matter, to activate and accelerate the natural decay of $\mathrm{U}$. Radiogenic heat was designed to be removed with the circulating water at room temperature to reduce the potential effect of thermal degradation. Oil generation from the irradiated organic matter confirmed that particles bombardment from the $U$ natural decay promoted oil production, with a maximum yield of $19.5 \mathrm{mg} \mathrm{g}^{-1}$ TOC. The produced oil was rich in asphaltene, aromatic compounds and high-molecular-weight compounds, and also had abundant low-maturity and intermediate products (e.g., alkenes, prist-1ene, $\mathrm{C}_{27}$-hop-17(21)-ene, and moretanes) in the saturated fraction. These results indicated that particle bombardment led to the radiolytic cracking of $\mathrm{C}-\mathrm{C}$ bonds, different with the traditional thermal degradation processes. Therefore, as a function of time and content, the natural irradiation from $\mathrm{U}$ decay should be taken into account, when evaluating the petroleum resources of Paleozoic and Proterozoic U-rich source rocks.

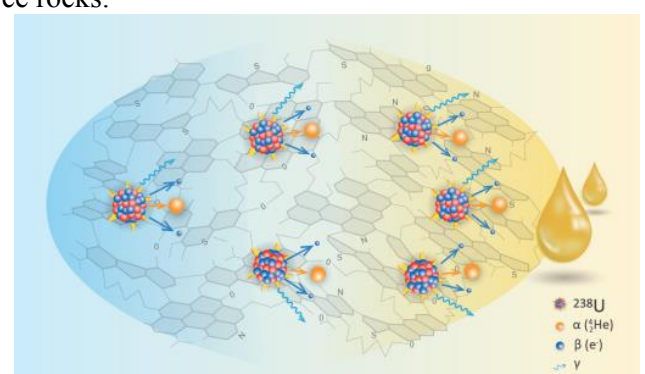

Figure 1 Oil generation from kerogen for the U irrdiation 